\title{
IASL 2009 in the Picture
}

\author{
Luisa Marquardt \\ IASL 2009 Conference Co-Chair \\ LIS Lecturer \\ University "Roma Tre", Rome
}

\begin{abstract}
This paper aims at introducing the $38^{\text {th }}$ IASL Conference, its aims and features, and presenting some reflections about the Italian edition of the Conference and, in general, on the school library as a crucial piece in the main mosaic of education and culture.
\end{abstract}

$38^{\text {th }}$ IASL Annual Conference, school libraries

\section{Introduction}

Ladies and Gentlemen, dear Colleagues and Friends - above all, Friends -,

I'm sincerely thanking the IASL Board Members for appointing me as the Co-Chair of this Conference and giving me the opportunity to work very closely with Prof. Donatella Lombello in setting up, with our team, this annual appointment. This conference is just held after an outstanding world library meeting - the $75^{\text {th }}$ IFLA WLIC - which gathered in Milan (Italy) about 4,000 attendees from all over the world last week and the IASL-IFLA Joint Meeting on "Reading in the Digital Age”, held just yesterday, Sept. $1^{\text {st }}$, in Padua.

Before introducing our first plenary session and its keynote speakers, I would like to spend a few words about this edition of the IASL Conference, a special one for Italy, since it is the first (and, hopefully, not the last one!) in this wonderful country, rich of history and culture.

\section{IASL 2009: Something Old, Something New...}

There is an old and popular English saying which sounds like this: "Something Old, Something New, Something Borrowed, Something Blue and a Silver Sixpence in Her Shoe”, items which any bride can't miss to take in account and wear when getting prepared herself for her wedding.

Preparing this meeting, as a bride-to-be, who is full of fear, desire, emotion, and who wishes herself a new life full of "good luck", we wanted to take in account "something old" in the sense of continuity, e.g., the formula of the IASL Conference, with the Flag the Awards Ceremonies, the combination of invited speakers and selected contributions, the Auction etc.

We have introduced "something new" as well. When looking at the programme, maybe some of you might have been surprised in finding in each plenary session there are two keynote speakers. In part this decision was made under the pressure of money restriction and organizational issues (e.g., the need of concentrating the simultaneous interpretation service in the morning). There is also another reason: we wanted contributions from different points of view, backgrounds, expertise - institutional, academic, professional - could be offered in order to stimulate reflections and debate. So, it shouldn't been felt as a diminishment the fact that we're going to have two keynotes per each morning plenary session. Something new is a renewed and closer collaboration 
with IFLA School Libraries and Resource Centers Section: a joint steering committee was established years ago, and at last we can see an improvement in communication, interaction, collaboration, in order to move together towards common goals. Something "new" was wanted for the exhibit area: a space free and open to the public, to those who are not a conference delegate, but want to have a look at the books and other items on display, and have the chance, for instance, of helping the IASL Auction or, hopefully, to join the IASL itself. In the exhibit area a visitor will find a joint desk devoted to organizations as UNESCO, IFLA, IBBY, ENSIL, Goethe Institut, US Information and Resource Center, and their projects and activities. That desk is here to underline new possibilities and perspectives for a tighter and effective collaboration. For instance, IFLA and IBBY will be holding their next annual conferences in 2010 in Europe, in Gothenburg (Sweden) and Santiago de Compostela (Spain): a good chance for the library community to gather once again in the "Old Continent". But, please, don't miss to consider to visit the "2010 IASL Conference in Brisbane" booth where a challenging opportunity for "jumping" in the Australian (school) library world is offered. Something still very new are topics like health education through the school library or the principal's role in the school library services development.

“Something Borrowed”: we borrowed many things from our colleagues, many suggestions and tips to carry their luck over to this Conference. One of the things we borrowed, e.g. a continuous and helpful support from many persons and a special one - Karen Bonanno - who patiently and efficiently assisted us in many ways. We borrowed from IASL 2008 the Conference Booklet format. As anything borrowed has to be returned afterwards, we return our thanks to Blanche Woolls, Kristin Fontichiaro and their 2008 Team. We return to this magnificent audience this new edition of the Conference booklet with some integrations, as the posters, which we supposed to be useful to have them published here in order to facilitate the attendance to their presentation. Of course, we had to borrow a lot of time from the Conference team, specially from the Conference Committee members, and their coordinators Marisa Trigari and Lourense Das: we think the Conference program developed is balanced and can stimulate interest and positive outcomes.

"Something Blue": the blue colour is considered a "noble" one, representing loyalty, purity, fidelity etc. We got trust and faithfulness from many international, national and local institutions and (actually not so many...) vendors: we hope to give them back the visibility they deserve and the satisfaction of our Conference attendees.

"And a silver six pence in her shoe": according to an ancient tradition, a six pence coin in the bride's shoe would bring the new couple a wealthy future, but... Our winter shoes had a big hole, we are now in Summer and our sandals, as they are open, they can't unfortunately hold any six pence (a penny neither...). We wished to offer more, but money restriction have been affecting the whole organization since the very first moment. The support from prestigious institutions, above all the "Università di Padova - Dipartimento di Scienze dell'Educazione", the "Regione Veneto", the "Città di Abano", the ANSAS (the National Agency for the Self Government of Schools), the collaboration at international level - e.g., with the Goethe Institut and the U.S. Office of Public Affairs -, and all of you, with your decision to attend this meeting, have anyway made this Conference real.

In the school library, something old, something new... In some way, the "Something Old, Something New-approach”, could be applied at the school library context.

The school library doesn't stand alone, can't stand alone: it belongs to the school community, it's a vital part of the local community as well. New programs, services, activities have to be established and exploited by the school library according to its school's mission. Its 
educational aims should be always taken in account. For instance, the school library could establish and maintain an institutional repository of the school in order to collect and exploit over the years the documentation developed by pupils and their teaching team within educational and research projects on a specific topic. This documentation may represent an invaluable source of information about learning and teaching processes and activities, useful both to that school itself and the wider community of students and scholars.

The school library should be open and welcome approaches and methodologies which guide, assist and foster the whole educational and learning process and make it effective. In the meantime, inspiration and innovation from the social, cultural, technological context should stimulate and enrich the school library, as well.

The school library has two doors (this is not a new concept): one is open towards the school, the teaching and learning process and activities; the other one is open towards the external context. It also has a double heart which beats for the joy of reading and for the pleasure of researching. We should keep in our mind very clear they are not separated, otherwise we'd risk to suggest the "sorrow" of studying and researching, opposite to the "pleasure" that reading a novel gives its reader. The school library usually promotes or collaborates in reading promotion: it should give an decisive contribution even in other fields (such as science education) and promote a proactive attitude in pupils.

We see in our experience that pupils are naturally attracted by colours, shapes, variety, etc.: the school library should borrow some new concepts and ideas about arranging its space and resources in a more attractive and stimulating way. The school library should be a rich, efficient and reliable source of information and a gateway to further information, that is not available in the school. The school library should always have a "silver six pence”: financial cuts don’t affect only the school library itself, they heavily affect the way our pupils and our students learn, they affect their learning environment and personal development, they affect the future of our societies.

We could go on reflecting on our profession - this can't stand alone and shouldn't be isolated at all: there are many areas in common with education and LIS where theory, practice and experiences could be shared -, but it's time to get back to our Conference. So, let's enjoy it in its several aspects - scientific, professional, cultural, social -, let's take the most out of it, and bring back to our schools, libraries, universities new ideas, stimuli, alliances and partnerships!

\section{Biographical Notes}

Luisa Marquardt has worked as a lecturer of Library and Information Science at the Faculty of Education, University "Roma Tre" (Rome, Italy) since 2003. She worked over 20 years as a Library Manager in high schools in charge of the County Council of Rome since the late '70s.

\section{Statement of Originality}

This statement certifies that the paper above is based upon original research undertaken by the author and that the paper was conceived and written by the author alone and has not been published elsewhere. All information and ideas from others are referenced. 